\title{
Addressing the Social Determinants of Subjective Wellbeing: The Latest Challenge for Social Policy
}

\section{CHRISTOPHER DEEMING}

School of Geographical Sciences, University of Bristol, University Road, Clifton, Bristol BS8 1SS. Email: Chris.Deeming@bristol.ac.uk

\begin{abstract}
The idea that the happiness and wellbeing of individuals should shape government policy has been around since the enlightenment; today such thinking has growing practical policy relevance as governments around the world survey their populations in an effort to design social policies that promote wellbeing. In this article, we consider the social determinants of subjective wellbeing in the UK and draw lessons for social policy. Survey data are taken from the 'Measuring National Wellbeing Programme' launched by the UK's Office for National Statistics in 2010. For the empirical strategy, we develop bivariate and multivariate logistic regression models, as well as testing for interaction effects in the data. The findings show that wellbeing is not evenly distributed within the UK. Socio-demographic characteristics such as age, gender, ethnicity, employment, household composition and tenure all matter, as does health status. Influencing population wellbeing is inherently complex, though, that said, there is a clear need to place greater emphasis on the social, given the direction of current policy.
\end{abstract}

\section{Introduction}

In this article, we draw on national social survey data to identify and report on the social determinants of wellbeing in the UK and we consider some of the challenges the findings present for social policy. In the first section, we review some of the latest developments in subjective wellbeing (SWB) research, and we consider how SWB is now being measured by the Office for National Statistics (ONS) in the UK. In our empirical section, we develop bivariate and multivariate logistic regression models, as well as testing for interaction effects, in order to assess the socio-economic and demographic characteristics that help to predict wellbeing in the national population. We do so using four global measures of SWB. Finally, in the last section, we consider some of the potential social policy implications raised by the findings. Before describing the study methods and results, and discussing their implications, we review the UK's new 'Measuring National Wellbeing (MNW) Programme'. 


\section{Measuring subjective wellbeing and the policy process}

It is now widely accepted that traditional economic measures are necessary, but not sufficient, to reflect national wellbeing (Stiglitz et al., 2010). In recent years, measures of SWB have been refined to help monitor social progress and policy (Taylor, 2011). Governments around the world - including the British government - are increasingly concerned about the quality of life and the environment in which we live, as well as the traditional measures of GDP and economic growth that help to define living standards in society (Stratton, 2010).

The measurement of SWB has advanced rapidly over the last two decades (Diener, 2009a). Researchers usually draw a basic distinction between self-reported wellbeing, i.e. SWB, and the more objective non-self-reported assessments and measures (Diener, 2009b). In this article, we are only interested in subjective measures. Broadly speaking, as Dolan and Metcalfe (2012) maintain, there are three main theoretical strands underpinning the measurement of SWB which are relevant to this study:

- The 'evaluative' approach to SWB asks individuals to reflect on their life and make a cognitive assessment of how their life is going overall, or on certain aspects of their life. 'Life satisfaction', as used here, is dependent on a global appraisal of life.

- The 'hedonic' approach seeks to measure people's feelings and emotions as Diener (2009a) observes. General states of 'happiness' and 'anxiety' are used in this study, which form part of the more global cognitive appraisal of wellbeing.

- The 'eudemonic' approach, sometimes referred to as the psychological functioning or flourishing approach, draws on self-determination theory and taps into our sense of purpose and meaning in life, with notions of the 'worthwhile' life employed here.

In the classical philosophical tradition, interpretations of eudaimonia and human flourishing were defined by Aristotle as the highest human good and included such things as spiritual fulfilment and civic virtue (Bok, 2010). Naturally, the MNW Programme does not cover all aspects of 'eudemonic wellbeing' but there are of course other more objective measures of human wellbeing, of equality and human rights, and capability, being developed and refined for the development of social policy (Dean, 2010).

Interest in the idea of national accounts for monitoring population wellbeing is growing (Diener et al., 2009a) and SWB measures and findings are increasingly being used to inform and appraise social policy (Dolan and Metcalfe, 2012). In the UK, the MNW Programme was launched by the ONS in 2010, as a response to the growing domestic as well as international policy imperative (Table 1). The programme is designed to provide new statistical measures of SWB, urgently needed to help monitor social progress and shape the direction of social policy. Following the recommendations of Dolan and Metcalfe (2012), and those of 
TABLE 1. Key developments in measuring wellbeing

1994 United Nations publishes first Human Development Index.

2000 First issue of the Journal of Happiness Studies is published.

2002 UK Cabinet Office Strategy Unit Report, Life Satisfaction: The State of Knowledge and Implication for Government.

2007 European Commission initiates the 'Beyond GDP' project.

2008 President Sarkozy establishes the Commission on the Measurement of Economic Performance and Social Progress.

2009 OECD starts Better Life Initiative and Work programme on measuring wellbeing and progress.

2010 The US government establishes a Commission on Key National Indicators, allocating $\$ 70$ million to the project.

2010 The UK Office for National Statistics begins a programme to develop statistics to measure national wellbeing.

2011 The US National Research Council, the National Institute on Aging and the UK Economic and Social Research Council jointly support an expert panel on subjective wellbeing and public policy.

2011 UN General Assembly Resolution on Happiness 65/309.

2012 UN High-Level meeting on happiness and wellbeing. Release of the UN World Happiness Report.

Source: Parliamentary Office of Science and Technology (POST) (2012: 2).

Stiglitz et al. (2010), ONS now attempts to capture the three different components of SWB in household surveys (ONS, 2011a, 2011b, 2011c, 2012).

The ONS have discussed their emerging survey findings on SWB in various publications (e.g., ONS, 2011a, 2011b). Although their investigations are informative, the ONS has, however, deliberately stopped short of any sophisticated analysis of data, including the sort of multivariate modelling that is required to shed greater light on the complexity of SWB in the social world (Byrne, 2011). To-date, ONS reports have largely been descriptive, showing basic cross-tabulations and average estimates of SWB for different sections of the population (as shown in Table 2, for example). Their findings do not reveal with any degree of certainty which sections of the British population are particularly vulnerable to experiencing low levels of SWB. Yet we know from the international research literature that a range of socio-demographics (e.g., age, gender, income, household composition, unemployment and disability) can help to explain wellbeing (e.g., Clark and Oswald, 1994; Stack and Eshleman, 1998; Layard, 2005; Clark, 2006; Blanchflower and Oswald, 2008; Dolan et al., 2008; Oswald and Powdthavee, 2008; Diener et al., 2009b). There is, therefore, a pressing need to analyse the new social survey data with multivariate regression and modelling techniques (where all the different socio-demographic characteristics are taken together and controlled for) in order to shed more light on the correlates of SWB in the UK. Although officials have not undertaken this work themselves, they are actively encouraging the research community to do so. ${ }^{1}$ 
TABLE 2. Average (mean) ratings for the four overall subjective - monitoring questions by personal characteristics (sex, age, self-reported health and long standing illness or disability: Great Britain, adults aged 16 and over)

\begin{tabular}{llcccc}
\hline & & Life satisfaction & Worthwhile & Happy & Anxious \\
\hline Sex & Men & 7.3 & 7.5 & 7.3 & 3.3 \\
Age & Women & 7.5 & 7.8 & 7.5 & 3.6 \\
& $16-19$ & 7.8 & 7.8 & 7.8 & 3.7 \\
& $20-24$ & 7.4 & 7.7 & 7.3 & 3.3 \\
& $25-29$ & 7.1 & 7.4 & 7.2 & 3.6 \\
& $30-34$ & 7.4 & 7.5 & 7.4 & 3.3 \\
& $35-39$ & 7.0 & 7.5 & 7.1 & 3.7 \\
& $40-44$ & 7.3 & 7.6 & 7.2 & 3.7 \\
& $45-49$ & 7.2 & 7.5 & 7.2 & 3.3 \\
& $50-54$ & 7.4 & 7.7 & 7.2 & 3.5 \\
& $55-64$ & 7.4 & 7.7 & 7.4 & 3.6 \\
Health & $65-74$ & 7.9 & 7.9 & 7.8 & 3.0 \\
& 75 or over & 7.7 & 7.4 & 7.6 & 3.1 \\
& Very good & 7.9 & 8.1 & 7.9 & 3.1 \\
& Good & 7.4 & 7.6 & 7.4 & 3.4 \\
& Fair & 6.8 & 7.0 & 6.7 & 4.0 \\
Illness/disability & Bad & 5.5 & 6.0 & 5.5 & 5.1 \\
& Very bad & 4.2 & 4.6 & 4.8 & 5.0 \\
& Yes & 7.0 & 7.2 & 7.0 & 3.8 \\
& No & 7.6 & 7.8 & 7.6 & 3.3 \\
\hline
\end{tabular}

Source: Reference tables for investigation into subjective well-being data from the ONS Opinions Survey (ONS, n.d.).

TABLE 3. Overall measures of subjective wellbeing

Variable Variable label Monitoring question

MCZ_1 Life satisfaction Overall, how satisfied are you with your life nowadays?

MCZ_2 Worthwhile Overall, to what extent do you feel the things you do in your life are worthwhile?

MCZ_3 Happy Overall, how happy did you feel yesterday?

MCZ_4 Anxious Overall, how anxious did you feel yesterday?

Source: ONS (2011c, 2012).

\section{Methods}

Logistic regression, in SPSS (version 19.0), was used to identify the social determinants of SWB in the national population. We use the four global measures of SWB discussed above (with the relevant ONS variable codes shown in Table 3), and we draw on the range of socio-demographic factors captured by the ONS survey (Table 4) to examine the risk and relative odds of low SWB in the British population (ONS survey described in the Appendix below).

Logistic regression is a statistical technique that belongs to the theoretical framework of the General Linear Models (GLM), described by Dobson (2001), 
TABLE 4. Dependant variables in the model

\begin{tabular}{|c|c|c|}
\hline Variable & Description & Specification in the study \\
\hline AGEX & Age & $\begin{array}{l}\text { Age may help to explain wellbeing in the } \\
\text { British population. Here age is recoded into } \\
\text { six groups. }\end{array}$ \\
\hline RSEX & Sex/gender & $\begin{array}{l}\text { Sex/gender may help to explain wellbeing in } \\
\text { the British population (male/female). }\end{array}$ \\
\hline Ethnicity & $\begin{array}{l}\text { To which of these groups do } \\
\text { you belong? }\end{array}$ & $\begin{array}{l}\text { Ethnicity may help to explain wellbeing. } \\
\text { Responses to this question are recoded into } \\
\text { two groups: 'white' and 'black and minority } \\
\text { ethnic' (BME). }\end{array}$ \\
\hline DVILO4a & $\begin{array}{l}\text { DV for ILO in employment } \\
\text { (four categories) }\end{array}$ & $\begin{array}{l}\text { Being in work may help to explain wellbeing, } \\
\text { here we have four categories: } \\
\text { - 'in employment (exc. unpaid family } \\
\text { workers)' } \\
\text { - 'unpaid family workers' } \\
\text { - 'unemployed' (ILO definition) } \\
\text { - 'economically inactive'. }\end{array}$ \\
\hline sumgross & Gross annual income & $\begin{array}{l}\text { Income may help to explain wellbeing. } \\
\text { Responses to this question are recoded into } \\
\text { income quintiles. }\end{array}$ \\
\hline Ten 1 & Housing tenure & $\begin{array}{l}\text { Three groups: } \\
\text { - 'home-owner (including those with a } \\
\text { mortgage)' } \\
\text { • 'private renter' } \\
\text { - 'social housing (including housing } \\
\text { association accommodation or local } \\
\text { authority housing)'. }\end{array}$ \\
\hline DeFactı & $\begin{array}{l}\text { De facto marital status } \\
\text { (grouped) }\end{array}$ & $\begin{array}{l}\text { Household composition may help to explain } \\
\text { wellbeing. Responses to this question are } \\
\text { recoded into two groups: } \\
\text { - 'couple' (includes married, cohabiting, } \\
\text { civil partner) } \\
\text { - 'single' (living alone, inc. divorced, } \\
\text { separated, widowed). }\end{array}$ \\
\hline QHealth & How is your health in general? & $\begin{array}{l}\text { Self-reported health may help to explain } \\
\text { wellbeing. There are five categories: 'very } \\
\text { good', 'good', 'fair', 'bad' and 'very bad'. }\end{array}$ \\
\hline LSIll & $\begin{array}{l}\text { Have any long-standing illness, } \\
\text { disability or infirmity? }\end{array}$ & $\begin{array}{l}\text { Long-standing illness and disability may help } \\
\text { to explain levels of wellbeing in the British } \\
\text { population. Responses to this question are } \\
\text { recoded into two groups: 'yes' and 'no'. }\end{array}$ \\
\hline highed $4_{4}$ & $\begin{array}{l}\text { What is the highest level of } \\
\text { qualification? }\end{array}$ & $\begin{array}{l}\text { Education - measured by educational } \\
\text { attainment - may help to explain wellbeing } \\
\text { in the British population. There are three } \\
\text { categories: 'Degree or equivalent', 'Below } \\
\text { degree level', 'None (no qualifications)'. }\end{array}$ \\
\hline $\mathrm{NSECAC}_{3}$ & $\begin{array}{l}\text { National Statistics } \\
\text { Socio-economic } \\
\text { Classification (NS-SEC) }\end{array}$ & $\begin{array}{l}\text { Social class and socio-economic position may } \\
\text { help to explain patterns of wellbeing (we use } \\
\text { the standard NS-SEC } 8 \text { classification). }\end{array}$ \\
\hline GorA & Government Office Region & $\begin{array}{l}\text { Wellbeing in Britain may vary by geography } \\
\text { and region of residence. }\end{array}$ \\
\hline
\end{tabular}

Source: ONS (2011c, 2012). 
and is ideally suited to situations where a continuous response variable, such as SWB, has been categorised as a dichotomy using binary coding (Hosmer and Lemeshow, 2000). For the analysis therefore, we have created new binary variables on each measure of wellbeing: for 'unhappiness', 'anxiety', 'dissatisfaction' and feeling that life is 'unfulfilled'. Persons scoring 4 or below on the question about 'happiness', for instance, are coded as (1) 'unhappy', while those scoring 5 or above are coded as (o) 'happy'. This dichotomy was repeated for the other measures of SWB. Respondents who did not answer the survey questions on wellbeing are not included in this study.

The empirical strategy follows logical sequential steps. First, our bivariate logit models establish the relative odds of wellbeing, along the different dimensions, by the range of individual and household characteristics, but without taking account of any of the other variables (the results are shown in Table 5). A bivariate model is a fairly simple one that shows the relationship between two variables, although many predictive factors are likely to be interrelated - there are often clear links between age, health and income for instance. There is a need for multivariate analysis. Importantly, the relative odds of reporting or predicting high or low levels of SWB independent of other variables can be calculated using a multivariate model (independent here means after taking account of all of the other demographic and socio-economic variables in the model). Much of the discussion below focuses on the findings from the multivariate analysis shown in Table 6, with cross-referencing to the bivariate findings in order to help understand some of the complexity surrounding the social determinants of SWB. Finally, we examine for covariance and interactions between variables in the main effects multivariate model (results are shown in Tables 6 and 7 ). ${ }^{2}$

In the statistical models, those who report being 'happy', or 'satisfied' with life, not suffering with 'anxiety' or leading 'worthwhile' lives (being the majority in each case) form the base in each model. Logistic regression models are then able to calculate the relative odds of being 'unhappy', 'dissatisfied', 'anxious' or leading an 'unfulfilled' life by the range of socio-demographic factors shown in Table 4. The odds compare the chances of being 'happy' verses being 'unhappy' etc., with the relative odds reflecting the odds of one particular category compared to the reference. These odds ratios show the strength and the direction of the predictors - asterisks indicate the level of significance and the 'base case' is always 1.0o. All study calculations are weighted (see Appendix) to correct for non/differential response rates, in order to ensure study estimates relate to the national picture (Crockett, 2006).

\section{Results}

A first step in the analysis was to examine the survey data relating to SWB in the British population. Overall, the survey results suggest that wellbeing in the 
TABLE 5. The relative odds of wellbeing (bivariate model)

\begin{tabular}{|c|c|c|c|c|}
\hline & $\begin{array}{c}\text { 'Unhappy' } \\
\text { (i) }\end{array}$ & $\begin{array}{c}\text { 'Dissatisfied' } \\
\text { (ii) }\end{array}$ & $\begin{array}{l}\text { 'Unfulfilled' } \\
\text { (iii) }\end{array}$ & $\begin{array}{c}\text { 'Anxious' } \\
\text { (iv) }\end{array}$ \\
\hline \multicolumn{5}{|l|}{ Sex/gender } \\
\hline Male & 1.00 & 1.00 & 1.00 & 1.00 \\
\hline Female & 1.09 & $1.34^{*}$ & $1.45^{* *}$ & $0.82^{* *}$ \\
\hline \multicolumn{5}{|l|}{ Ethnicity } \\
\hline 'White' & 1.00 & 1.00 & 1.00 & 1.00 \\
\hline $\mathrm{BME}$ & $1.59^{* *}$ & $1.66^{* *}$ & $1.53^{*}$ & $1.51^{* * *}$ \\
\hline \multicolumn{5}{|l|}{ Age } \\
\hline $16-24$ & 1.00 & 1.00 & 1.00 & 1.00 \\
\hline $25-44$ & 1.18 & 1.44 & 1.06 & 1.19 \\
\hline $45-54$ & 1.27 & 1.54 & 1.01 & 1.03 \\
\hline $55-64$ & 0.97 & 1.22 & 0.82 & 1.22 \\
\hline $65-74$ & 0.82 & 0.89 & 0.86 & 0.90 \\
\hline $75+$ & 0.88 & 1.28 & $1.75^{*}$ & 0.76 \\
\hline \multicolumn{5}{|l|}{ Health } \\
\hline Very good & 1.00 & 1.00 & 1.00 & 1.00 \\
\hline Good & $1.62^{* * *}$ & $1.90^{* * *}$ & $2.53^{* * *}$ & $1.19^{*}$ \\
\hline Fair & $2.97^{* * *}$ & $3.82^{* * *}$ & $6.50^{* * *}$ & $1.79^{* * *}$ \\
\hline Poor & $8.14^{* * *}$ & $13.1^{* * *}$ & $19.7^{* * *}$ & $2.74^{* * *}$ \\
\hline Very poor & $11.2^{* * *}$ & $25.1^{* * *}$ & $33 \cdot 9^{* * *}$ & $2.66^{* *}$ \\
\hline \multicolumn{5}{|l|}{ Disability } \\
\hline No rated disability & 1.00 & 1.00 & 1.00 & 1.00 \\
\hline Reported disability & $1.95^{* * *}$ & $2.29^{* * *}$ & $2.96^{* * *}$ & $1.44^{* * *}$ \\
\hline \multicolumn{5}{|l|}{ Education } \\
\hline Degree & 1.00 & 1.00 & 1.00 & 1.00 \\
\hline Below degree & $1.54^{* *}$ & 1.25 & $1.61^{*}$ & 1.03 \\
\hline No formal qualifications & $1.92^{* * *}$ & $1.74^{* *}$ & $2.53^{* * *}$ & 1.08 \\
\hline \multicolumn{5}{|l|}{ Labour force status } \\
\hline In employment & 1.00 & 1.00 & 1.00 & 1.00 \\
\hline Unemployed & $2.13^{* * *}$ & $3.93^{* * *}$ & $3.58^{* * *}$ & 1.30 \\
\hline Economically inactive & 1.20 & $1.56^{* * *}$ & $2.40^{* * *}$ & 1.11 \\
\hline \multicolumn{5}{|l|}{ Socio-economic position } \\
\hline Managerial/professional & 1.00 & 1.00 & 1.00 & 1.00 \\
\hline Intermediate & 0.98 & 1.34 & 1.02 & 0.91 \\
\hline Manual workers & $1.46^{* * *}$ & $2.03^{* * *}$ & $2.14^{* * *}$ & 0.99 \\
\hline \multicolumn{5}{|l|}{ Income quintile } \\
\hline Top & 1.00 & 1.00 & 1.00 & 1.00 \\
\hline Second & 0.92 & 1.44 & 1.28 & 0.83 \\
\hline Middle & 1.05 & $2.17^{* *}$ & $2.22^{* *}$ & 1.03 \\
\hline Fourth & $1.43^{*}$ & $2.84^{* * *}$ & $3.70^{* * *}$ & $1.31^{*}$ \\
\hline Bottom & $1.42^{*}$ & $3 \cdot 30^{* * *}$ & $3.17^{* * *}$ & $1.28^{*}$ \\
\hline \multicolumn{5}{|l|}{ Household composition } \\
\hline Couple & 1.00 & 1.00 & 1.00 & 1.00 \\
\hline Single person & $1.76^{* * *}$ & $2.72^{* * *}$ & $3 \cdot 33^{* * *}$ & 1.06 \\
\hline \multicolumn{5}{|l|}{ Housing tenure } \\
\hline Home owner & 1.00 & 1.00 & 1.00 & 1.00 \\
\hline Private rental & $1.91^{* * *}$ & $1.81^{* * *}$ & $2.26^{* * *}$ & 1.15 \\
\hline Social housing & $2.35^{* * *}$ & $3.12^{* * *}$ & $4.01^{* * *}$ & 1.04 \\
\hline
\end{tabular}


TABLE 5. Continued

\begin{tabular}{lcccc}
\hline & $\begin{array}{c}\text { 'Unhappy' } \\
(\mathrm{i})\end{array}$ & $\begin{array}{c}\text { 'Dissatisfied' } \\
(\mathrm{ii})\end{array}$ & $\begin{array}{c}\text { 'Unfulfilled' } \\
\text { (iii) }\end{array}$ & $\begin{array}{c}\text { 'Anxious' } \\
\text { (iv) }\end{array}$ \\
\hline $\begin{array}{l}\text { Region of residence } \\
\text { North East }\end{array}$ & & & \\
North West & 1.00 & 1.00 & 1.00 & 1.00 \\
Yorkshire \& the Humber & 0.74 & 0.75 & 0.79 & $0.67^{*}$ \\
East Midlands & 0.79 & 0.88 & 1.02 & $0.59^{* *}$ \\
West Midlands & 0.67 & 0.61 & 0.74 & $0.68^{*}$ \\
East of England & 0.93 & 1.01 & 0.79 & 0.77 \\
London & 0.73 & 0.77 & 0.69 & $0.54^{* * *}$ \\
South East & 1.14 & 1.74 & 1.61 & 0.87 \\
South West & 0.61 & 0.72 & 0.55 & 0.72 \\
Wales & $0.51^{*}$ & 0.70 & 0.63 & 0.77 \\
Scotland & 0.87 & 0.92 & 1.29 & $0.67^{*}$ \\
\hline
\end{tabular}

Notes: Significance levels: ${ }^{*}<0.05 ;^{* *}<0.01 ;{ }^{* * *}<0.001$.

national population is largely positive, not negative, and this is to be expected (Deaton, 2008). We find that most people in the UK, 88.6 per cent, are 'happy', leaving 11.4 per cent of the population who are not. We also find the overwhelming majority of people report they are 'satisfied' with their life - 92.4 per cent compared to just 7.6 per cent who are not. According to the survey, most people in Britain (94.4 per cent) appear to lead 'meaningful' lives; only 5.6 per cent claim life is not 'fulfilled'. 'Anxiety' is more prevalent however: over a third of people (37.4 per cent) report feeling 'anxious' about life when surveyed, leaving 62.6 per with little or no such 'anxiety'. The study findings are now discussed under the four relevant headings.

\section{'Happiness'}

In Table 6 (column (i)), we observe that age, ethnicity, health, education, household composition and housing tenure continue to have an impact on 'happiness' in Great Britain, even after controlling for all other factors in the model, as does geographical region. Interestingly, income was a significant predictor of 'happiness' in the bivariate analysis, but the income effects on 'happiness' are lost after controlling for all of the other variables. This suggests that the effects of income on 'happiness' are moderated by other socio-demographic characteristics in the model, notably by health status, according to the strong interactions with income (observed in Table 7), and employment status to a lesser degree.

Gender, social class and labour-force status do not appear to have much of an impact on 'happiness' after controlling for everything else; neither does disability. Disability was a significant predictor of 'unhappiness' in the 
TABLE 6. The relative odds of wellbeing (multivariate model)

\begin{tabular}{|c|c|c|c|c|}
\hline & $\begin{array}{c}\text { 'Unhappy' } \\
\text { (i) }\end{array}$ & $\begin{array}{c}\text { 'Dissatisfied' } \\
\text { (ii) }\end{array}$ & $\begin{array}{l}\text { 'Unfulfilled' } \\
\text { (iii) }\end{array}$ & $\begin{array}{l}\text { 'Anxious' } \\
\text { (iv) }\end{array}$ \\
\hline \multicolumn{5}{|l|}{ Sex/gender } \\
\hline Female & 1.00 & 1.00 & 1.00 & 1.00 \\
\hline Men & 1.05 & 1.30 & $1.63^{* *}$ & $0.82^{*}$ \\
\hline \multicolumn{5}{|l|}{ Ethnicity } \\
\hline 'White' & 1.00 & 1.00 & 1.00 & 1.00 \\
\hline BME & $1.59^{*}$ & 1.18 & 1.18 & 1.24 \\
\hline \multicolumn{5}{|l|}{ Age } \\
\hline $16-24$ & 1.00 & 1.00 & 1.00 & 1.00 \\
\hline $25-44$ & 1.18 & $2.13^{*}$ & 1.29 & 1.18 \\
\hline $45-54$ & 1.13 & $2.37^{*}$ & 1.07 & 1.01 \\
\hline $55-64$ & 0.77 & 1.11 & 0.64 & 1.00 \\
\hline $65-74$ & 0.56 & 0.98 & 0.50 & 0.73 \\
\hline $75+$ & $0.44^{*}$ & 1.07 & 0.99 & 0.74 \\
\hline \multicolumn{5}{|l|}{ Health } \\
\hline Very good & 1.00 & 1.00 & 1.00 & 1.00 \\
\hline Good & $1.43^{*}$ & $2.08^{* * *}$ & $2.03^{* *}$ & $1.25^{* *}$ \\
\hline Fair & $3.13^{* * *}$ & $5.66^{* * *}$ & $6.70^{* * *}$ & $1.84^{* * *}$ \\
\hline Poor & $7.90^{* * *}$ & $18.1^{* * *}$ & $19.6^{* * *}$ & $2.73^{* * *}$ \\
\hline Very poor & $10.3^{* * *}$ & $53.8^{* * *}$ & $29.8^{* * *}$ & $3.28^{* * *}$ \\
\hline \multicolumn{5}{|l|}{ Disability } \\
\hline No rated disability & 1.00 & 1.00 & 1.00 & 1.00 \\
\hline Reported disability & 1.07 & 0.95 & 1.10 & 1.18 \\
\hline \multicolumn{5}{|l|}{ Education } \\
\hline Degree & 1.00 & 1.00 & 1.00 & 1.00 \\
\hline Below degree & $1.65^{* *}$ & 1.15 & 1.62 & $1.21^{*}$ \\
\hline No formal qualifications & $1.88^{* *}$ & 0.94 & 1.22 & 1.20 \\
\hline \multicolumn{5}{|l|}{ Labour force status } \\
\hline In employment & 1.00 & 1.00 & 1.00 & 1.00 \\
\hline Unemployed & 1.41 & $2.61^{* * *}$ & 1.65 & 1.15 \\
\hline Economically inactive & 0.93 & $0.73^{* *}$ & 1.08 & 0.92 \\
\hline \multicolumn{5}{|l|}{ Socio-economic position } \\
\hline Managerial/professional & 1.00 & 1.00 & 1.00 & 1.00 \\
\hline Intermediate & 0.80 & 1.22 & 0.74 & 0.82 \\
\hline Manual workers & 0.99 & $1.44^{*}$ & 1.24 & 0.87 \\
\hline \multicolumn{5}{|l|}{ Income quintile } \\
\hline Top & 1.00 & 1.00 & 1.00 & 1.00 \\
\hline Second & 0.83 & 1.29 & 0.98 & 0.83 \\
\hline Middle & 0.70 & 1.45 & 1.15 & 1.00 \\
\hline Fourth & 0.81 & 1.43 & 1.47 & 1.20 \\
\hline Bottom & 0.91 & $2.17^{*}$ & 1.27 & 1.16 \\
\hline \multicolumn{5}{|l|}{ Household composition } \\
\hline Couple & 1.00 & 1.00 & 1.00 & 1.00 \\
\hline Single person & $1.77^{* * *}$ & $2.79^{* * *}$ & $2.64^{* * *}$ & 0.97 \\
\hline \multicolumn{5}{|l|}{ Housing tenure } \\
\hline Home owner & 1.00 & 1.00 & 1.00 & 1.00 \\
\hline Private rental & $1.49^{*}$ & 1.06 & 1.25 & 1.03 \\
\hline Social housing & 1.04 & 1.17 & 1.32 & 0.80 \\
\hline
\end{tabular}


TABLE 6. Continued

\begin{tabular}{lcccc}
\hline & $\begin{array}{c}\text { 'Unhappy' } \\
(\mathrm{i})\end{array}$ & $\begin{array}{c}\text { 'Dissatisfied' } \\
(\mathrm{ii})\end{array}$ & $\begin{array}{c}\text { 'Unfulfilled' } \\
\text { (iii) }\end{array}$ & $\begin{array}{c}\text { 'Anxious' } \\
\text { (iv) }\end{array}$ \\
\hline Region of residence & & & & \\
North East & 1.00 & 1.00 & 1.00 & 1.00 \\
North West & 0.71 & 0.70 & 0.81 & 0.73 \\
Yorkshire \& the Humber & 0.66 & 0.94 & 1.15 & $0.64^{*}$ \\
East Midlands & 0.59 & 0.74 & 0.78 & 0.70 \\
West Midlands & 0.75 & 0.78 & 0.62 & 0.67 \\
East of England & $0.52^{*}$ & 0.72 & 0.70 & $0.59^{*}$ \\
London & 0.76 & 1.80 & 2.13 & 0.77 \\
South East & 0.58 & 0.95 & 0.77 & 0.76 \\
South West & $0.43^{*}$ & 0.93 & 0.71 & 0.86 \\
Wales & 0.84 & 0.71 & 1.34 & 0.82 \\
Scotland & 0.79 & 1.17 & 0.81 & 0.80 \\
\hline
\end{tabular}

Notes: Significance levels: ${ }^{*}<0.05 ;^{* *}<0.01 ;{ }^{* * *}<0.001$.

bivariate model, but has an independent effect in the multivariate analysis. In Table 5, for instance, the odds of adults who report a disability being 'unhappy' are twice those of non-disabled adults. However, the effects of disability are significantly diluted or covered by the inclusion of other variables in the model (suggesting evidence of multicollinearity here), ${ }^{3}$ particularly with the more global assessment of health status, itself a powerful predictor of SWB across all four dimensions (columns (i)-(iv)). We say more about interaction effects below.

Health status is a strong determinant of 'happiness'. Other things being equal, the odds of people in very poor health being 'unhappy' are ten times those of people in very good health (column (i)); the odds for those in poor health are eight times greater and three times greater for those who report their health is fair. The findings for socio-economic status are more curious; we find manual workers are significantly more likely to be 'unhappy' without controls, whereas the 'social class' effects on 'happiness' are clearly moderated with the controls in place. The results also show an age effect: people in the oldest age group (seventy-five-plus) are significantly more likely to be 'happy' than young people aged sixteen to twenty-four (Table 6). Belonging to a black and minority ethnic (BME) group also significantly increases the relative odds of being 'unhappy' by 60 per cent, compared to the majority 'White' British population. There are also important interactions between ethnicity and other variables in the multivariable model, which are discussed in the section on interactions below.

Education is also an important predictor of 'happiness', independent of other factors. The relative odds of being 'unhappy' increase significantly with lower levels of educational achievement. For example, the relative odds of reporting 
TABLE 7. The relative odds of wellbeing (significant interactions in the main effects model)

'Unhappy' 'Dissatisfied' 'Unfulfilled' 'Anxious'

(i)

(ii)

(iii)

(iv)

Income*Health

Second quintile good health

Middle quintile good health

Fourth quintile good health

Bottom quintile good health

Second quintile fair health

Middle quintile fair health

Fourth quintile fair health

Bottom quintile fair health

Second quintile poor health

Middle quintile poor health

Fourth quintile poor health

Bottom quintile poor health

Second quintile very poor health

Middle quintile very poor health

Fourth quintile very poor health

Bottom quintile very poor health

Income*Employment

Second quintile unemployed

Third quintile unemployed

Fourth quintile unemployed

Bottom quintile unemployed

Disability*Health

Disability good health

Disability fair health

Disability poor health

Disability very poor health

Health*Employment

Unemployed good health

Unemployed fair health

Unemployed poor health

Unemployed very poor health

Disability*Household Composition

Disability Single Person

Ethnicity*Employment

'White' Unemployment

BME Unemployment

Socio-economic position*Health

Intermediate good health

Intermediate fair health

Intermediate poor health

Intermediate very poor health

Manual good health

Manual fair health

Manual poor health

Manual very poor health

Socio-economic position*Education Intermediate Below Degree

Intermediate No Formal Qualifications

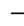

$-$

$-$

$$
-
$$

$-$

$$
-
$$

$2.27^{* *}$

$2.22^{* *}$

$2.24^{*}$

$-$

$4.74^{* * *}$

$4.50^{* * *}$

$7.50^{* * *}$

$10.12^{* * *}$

$12.98^{* * *}$

$7.06^{* *}$

$-$

$-$

$2.64^{*}$

$-$

$-$

$2.12^{* * *}$

$5.80^{* * *}$

$7.79^{* * *}$

$2.96^{* * *}$

$10.12^{* * *}$

$29.05^{* * *}$$$
-
$$$$
-
$$

$3.73^{* * *}$

$4.86^{* * *}$

$1.62^{* *}$

$-$

$3.74^{*}$

$4.53^{* * *}$

$14.46^{* * *}$

$1.85^{* * *}$

$2.17^{*}$

4.72 *

$-$

$2.32^{* *}$

$4.08^{* * *}$

$-$

$5.09^{* * *}$

2.47

$7.33^{* * *}$

$13.34^{* * *}$

$-$

$2.27^{* * * *}$

$5.43^{* * *}$

$-$

$3.48^{* * *}$

$11.25^{* * *}$

$10.64^{* * *}$

$33.00^{* * *}$

$-$

$2.44^{* * *}$

$\begin{array}{ll}- & - \\ - & - \\ - & -\end{array}$

- $1.52^{* *}$

- -

- $\quad-$

$4.81^{* * *} \quad 2.24^{* * *}$

$2.79^{*} \quad 2.20^{* * *}$

- $\quad-$

$3.31^{* *} \quad 1.89^{* *}$

$6.49^{* * *} \quad 3.01^{* * *}$

$10.78^{* * *} \quad 2.25^{*}$

$7.56^{*} \quad 5.60^{* *}$

$22.70^{* * *} \quad 3.38^{* *}$

$32.45^{* * *} \quad 5.63^{*}$

$28.05^{* * *} \quad 7.42^{*}$

-

- $\quad-$

- $\quad-$

$\begin{array}{ll}- & 1.95^{*}\end{array}$

2.00* -

$3.09^{* * *} \quad 1.88^{* * *}$

$11.09^{* * *} \quad 2.63^{* * *}$

$16.42^{* * *} \quad 3.22^{* *}$

-

6.31*** $\quad 1.88^{* *}$

$10.13^{* * *} \quad 2.37^{*}$

$1.84^{* *} \quad-$

-

$-$

- $\quad-$

$6.22^{* * *} \quad 2.10^{*}$

$8.71^{* * *} \quad-$

- $\quad-$

$3.01^{* * *} \quad 1.47^{*}$

$6.33^{* * *} \quad 1.94^{* *}$

$11.46^{* * *} \quad 2.13^{* *}$ 


\begin{tabular}{lcccc}
\hline & $\begin{array}{c}\text { 'Unhappy } \\
\text { (i) }\end{array}$ & $\begin{array}{c}\text { 'Dissatisfied' } \\
\text { (ii) }\end{array}$ & $\begin{array}{c}\text { 'Unfulfilled' } \\
\text { (iii) }\end{array}$ & $\begin{array}{c}\text { 'Anxious' } \\
\text { (iv) }\end{array}$ \\
\hline Manual Below Degree & - & - & - & - \\
Manual No Formal Qualifications & $1.46^{*}$ & $1.59^{*}$ & $1.76^{*}$ & - \\
$\begin{array}{l}\text { Household Composition*Tenure } \\
\text { Single Person Private Rental }\end{array}$ & $2.52^{* * *}$ & $2.18^{* *}$ & $2.48^{* *}$ & - \\
Single Person Social Housing & $1.81^{* *}$ & $1.84^{* *}$ & $2.45^{* * *}$ & - \\
\hline
\end{tabular}

Significance levels: ${ }^{*}<0.05 ;{ }^{* *}<0.01 ;{ }^{* * *}<0.001$.

'unhappiness' for those with educational attainment below the level of university degree is two-thirds greater than those with a university degree. Those with no formal qualifications display nearly twice the odds of reporting 'unhappiness' compared to people awarded a university degree. Household composition and housing tenure also matter (Table 6). The odds of single people living alone reporting 'unhappiness' are nearly 80 per cent greater than people living together as a couple. The odds of people in private rented accommodation being 'unhappy' are 50 per cent greater than those of a 'home-owner' (which includes people buying their own home with a mortgage). Furthermore, there appears to be regional variation in levels of 'happiness' across the country. The South West was found to be the 'happiest' place to live, being consistent with other surveys of SWB (Anand et al., 2009). The region is unremarkable on traditional economic indicators however, for example, GDP or GVA (ONS, 2011d), thus providing further caution against taking simple economic statistics as measures of social progress and wellbeing, as Harvie et al. (2008) argue.

\section{'Life satisfaction'}

On the 'life satisfaction' measure (column (ii)) of self-assessed wellbeing there are some notable differences compared to the findings for 'happiness'. Income and socio-economic position now matter. Manual workers and those at the bottom of the income distribution all report higher levels of 'dissatisfaction'. The odds of manual workers reporting 'dissatisfaction' with their lives, for instance, are more than 40 per cent greater than representatives from the managerial and professional classes. We also see in Table 6 that the odds of respondents in the lowest income quintile reporting 'dissatisfaction' are more than twice those of respondents in the top income quintile.

Age matters too in the multivariate analysis of 'life satisfaction'. As expected, during the period of middle age (twenty-five to fifty-four) there is increased 'dissatisfaction' with life. Although this familiar U-shape to wellbeing across the life-course is not fully understood, clearly this is a time of struggle for most 
adults, as they start to build a family and buy a home (Blanchflower and Oswald, 2008). Household composition also matters - as it did for 'happiness' - but not housing tenure on this measure of SWB. Other things being equal, the odds of single people living alone reporting to be 'dissatisfied' are now three times greater than those of people living together as a couple.

Ethnicity appears to be less decisive on this particular dimension of wellbeing, at least after controlling for all the other variables in the multivariate analysis. People from BME backgrounds appear to experience the same or similar levels of 'life satisfaction' as the majority 'White' British population. However, since we observe significant levels of 'dissatisfaction' in the bivariate analysis we may wish to question the adjustments in the multivariate model. At times it may be problematic to give the appearance of having adjusted for, and thereby having 'removed', any socio-economic differences in the statistical model while much of it remains in real life (Karlsen et al., 2012). A similar picture is present in the findings on disability status. Adults with a disability appear more 'dissatisfied' with life in the bivariate analysis, and yet disability is no longer significant when all of the other variables are controlled for in the model. Again this suggests that it is the social barriers and some of the observed health effects that impinge upon those who report an impairment (Roulstone and Prideaux, 2012). In other words, it is the circumstances of living with a disability that matter rather than simply the notion or label of 'disability' itself. For example, the odds of being 'dissatisfied' for a disabled person living alone are nearly twice those of a disabled person living in a couple (Table 7). Good health is a strong determinant of 'life satisfaction' in the general population. The independent health effects observed are even more pronounced than those found on the measure of 'happiness'. For instance, the odds of reporting 'dissatisfaction' amongst people who claim their health is very poor are now over fifty times greater than those of people who report that their health is very good (Table 6). While the odds of 'unhappiness' for those in poor health are eighteen times greater and six times greater for those who claim only fair health.

Education was found to be an important predictor of 'happiness' but not so for 'life satisfaction'. There was little or no meaningful variation according to educational attainment. Being educated to university degree level appears to make no more difference to overall 'life satisfaction' than having no formal educational qualifications. Conversely, while labour market participation had little or no effect on 'happiness', employment now seemingly alters perceptions of 'life satisfaction'. The odds of an unemployed person being 'dissatisfied' with life are more than two-and-a-half times those of someone in work. Interestingly, someone who is 'economically inactive', having retired from paid work or being a full-time student, is much more likely to be 'satisfied' with life. ${ }^{4}$ Unlike the findings relating to 'happiness', we observe no meaningful difference in the global assessments of 'life satisfaction' by geographical region. In other words, 
'life satisfaction' appears to be fairly evenly distributed across the regions of Great Britain.

\section{'Fulfilled lives'}

Although research has yet to identify the precise constituents that add meaning to our lives, and help make them worth living, we can, nonetheless, consider some of the relative socio-demographics associated with the life 'fulfilled' (column (iii)). In many ways, the multivariate results for 'worthwhile lives' (a measure of 'eudemonic' wellbeing) mirror the study findings for global 'life satisfaction'. There are, however, a number of contrasting findings. Women, for instance, are significantly more likely to report a stronger sense of purpose and meaning to their lives than men. This is interesting, not least because we found no significant difference by sex/gender on the 'happiness' and global 'life satisfaction' measures of SWB.

Good health helps life to be fulfilled. The odds of leading 'unfulfilled lives' amongst people who self-report very poor health, for example, are now thirty times greater than those in very good health (Table 6). While the odds for those living in poor health are now twenty times greater, and over six times greater for those who report their health is fair. With health status and all other variables controlled for in the model, there was no significant difference on this measure of SWB between those who report a disability and those who do not. Again, this suggests that many of the issues and disadvantages experienced by people with a disability are located within the social and economic circumstances of everyday life (Roulstone and Prideaux, 2012). Living alone is consistently significant, as a person with a disability who lives alone displays nearly twice the odds of leading an 'unfulfilled life' compared with a disabled person who does not live alone (Table 7); as might be expected, good health is also highly significant.

Household composition makes an independent contribution to feeling 'fulfilled' about life. Couples display odds of reporting that their life is 'worthwhile' which are three times greater than those of single people living alone. Housing tenure, however, was not a good predictor on this measure of SWB. Age, ethnicity, education, income and social class appeared to play little or no significant role in shaping 'fulfilment', after controlling for other factors. The study findings also suggest no significant regional variation here. In other words, geographical region currently plays no major role in shaping the extent to which people feel their lives are 'fulfilled' and 'worthwhile'.

\section{'Anxious lives'}

Although women lead more meaningful lives, they also report significantly more general 'anxiety' compared to British men (column (iv)). Age and ethnicity are not especially important on this particular dimension of SWB. In the multivariate analysis, people with BME backgrounds experience the same or 
similar levels of 'stress' as people in the 'White' British population. There is the now familiar gradient with health status, but the observed differences here are not as pronounced as we found using the other measures of SWB. For instance, the odds of people in poor health being 'stressed' are three times those of people in very good health. This difference is highly significant, but the order of magnitude on the measures of 'life satisfaction' and 'worthwhile' life was far greater.

Household composition was not important here. Income, socio-economic position and labour force status do not appear to impact on 'anxiety' after controlling for other factors; neither does disability. The latter finding is very much in keeping with the other results for SWB in Table 6. Income and disability were significant predictors of 'anxiety' in the bivariate analysis, but the effects of income and disability continue to be moderated by the other socio-demographic variables - including health status - in the multivariate model. Again, we find strong interaction effects between income and self-rated health, along with disability and self-rated health (Table 7). These findings are explored below. People with lower levels of education tend to be more 'stressed' compared to those with higher education. The study findings also suggest that people living in Yorkshire and in the East of England are significantly less 'anxious' when all other factors in the model are controlled for.

\section{Interactions}

The results suggest that there is some correlation between some of the variables in the multivariate analysis. The effects of disability, for example, are significantly diluted or covered by the inclusion of other variables in the multivariate model shown in Table 6, particularly the more global assessment of health status; this is a powerful predictor of SWB across all four dimensions (columns (i)-(iv)). In the interaction models (Table 7), we observe strong interaction effects between states of health and disability, showing the impact of declining health on SWB. The results for 'life satisfaction' and 'fulfilment' are particularly pronounced. The odds of feeling 'dissatisfied' amongst adults with a disability who are in very poor health, for example, are now about thirty times those of a disabled adult in very good health. The interaction effects between disability and health illustrate the importance of good health for positive wellbeing. We also observe strong interaction effects between disability and household composition (Table 7). An adult with a disability living alone is significantly more likely to report low levels of SWB compared to an adult with a disability living with another person as a couple.

In Table 7, we find strong effects between income and self-rated health. As health declines, the odds of reporting low SWB increase substantially regardless of income; however, the effects are much more dramatic at the lower end of the income distribution (from the lower middle-income quintile to the bottom quintile). In addition, the evidence suggests that income makes more 
of a difference to general wellbeing during the earlier stages of adult life (twenty-five to forty-four), and in middle age (forty-five-to fifty-four) on the 'satisfaction' measure of SWB. Income appears to play a less significant role in shaping wellbeing in later life (seventy-five-plus), particularly for the measures of 'happiness' and 'stress' free living. However, the picture in Table 8 appears rather patchy. Younger adults living alone are more likely to report significantly low levels of SWB compared to older adults living alone. We also observe significant interactions between age and health as might be expected; adults aged twenty-five to fifty-four in poor health (including the very poor health category) tend to be significantly more 'unhappy' than older adults (fifty-five plus). Similarly, levels of 'dissatisfaction' and 'unfulfillment' also tail off with age.

There are also important interactions between ethnicity and other variables in the multivariable model. The odds of unemployed people in BME groups reporting being 'unhappy' are nearly four times greater than those of the majority 'White' British population, and their odds of reporting 'dissatisfaction' are nearly five times greater than this group (Table 7). Unemployed adults reporting poor health have significantly lower levels of SWB compared to adults with poor health who are in work. Employment does appear to confer some benefits on those who are able to work, even if their health is not good (Table 7). Unemployed disabled adults are more 'anxious' than disabled adults who are in work. Occupational 'social class' was associated with other powerful predictors of 'happiness', such as health and educational attainment. Manual workers in poor health (including the very poor health category) are shown to have the lowest levels of wellbeing, alongside manual workers without any formal qualifications. Household composition also matters; people living alone in rented accommodation or social housing face twice the odds of being 'unhappy', 'dissatisfied' and feeling 'unfulfilled' compared to single people who are homeowners (Table 7).

\section{Discussion}

It is now widely accepted that the measurement of SWB is central to the development of social policy. Measures that capture personal experience, moods, psychological functioning and people's cognitive assessments about how their life is going overall - when aggregated at the national population level - elucidate an important component of the wellbeing concept that can be applied to social policy (Graham, 2011). The emerging survey data on SWB in the UK, however, is currently underdeveloped for social policy purposes. In this article, we have considered the application of the survey data for understanding the social determinants of SWB, and here we reflect on how the new insights may be used to inform the development of social policy. A number of findings are particularly striking, and deserve comment given the direction of current policy in the UK. 
TABLE 8. The relative odds of wellbeing (significant interactions in the main effects model)

\begin{tabular}{|c|c|c|c|c|}
\hline & $\begin{array}{l}\text { 'Unhappy' } \\
\text { (i) }\end{array}$ & $\begin{array}{l}\text { 'Dissatisfied' } \\
\text { (ii) }\end{array}$ & $\begin{array}{l}\text { 'Unfulfilled' } \\
\text { (iii) }\end{array}$ & $\begin{array}{l}\text { 'Anxious' } \\
\text { (iv) }\end{array}$ \\
\hline \multicolumn{5}{|l|}{ Age*Health } \\
\hline 25-44 good health & - & - & - & - \\
\hline $25-44$ fair health & $3.23^{* *}$ & - & $6.30^{* * *}$ & - \\
\hline $25-44$ poor health & $18.69^{* * *}$ & $4.78^{* * *}$ & $39.55^{* * *}$ & $6.15^{* * *}$ \\
\hline $25-44$ very poor health & $17.23^{*}$ & $33.82^{* * *}$ & $25.98^{* * *}$ & - \\
\hline 45-54 good health & - & - & - & - \\
\hline 45-54 fair health & $2.39^{* *}$ & - & $4.27^{* * *}$ & - \\
\hline 45-54 poor health & $5.88^{* * *}$ & $23 \cdot 32^{* * *}$ & $22.22^{* * *}$ & - \\
\hline $45-54$ very poor health & $12.04^{*}$ & $47.88^{* * *}$ & $7 \cdot 32^{*}$ & - \\
\hline $55-64$ good health & - & - & - & - \\
\hline $55-64$ fair health & $2.74^{* * *}$ & $2.43^{*}$ & $3.52^{* *}$ & - \\
\hline $55-64$ poor health & - & $10.66^{* * *}$ & $4.27^{*}$ & - \\
\hline $55-64$ very poor health & $4.60^{*}$ & $34.57^{* * *}$ & $29.45^{* * *}$ & $6.81^{*}$ \\
\hline $65-74$ good health & - & - & - & - \\
\hline $65-74$ fair health & - & $5.37^{* *}$ & - & - \\
\hline $65-74$ poor health & - & $4.21^{*}$ & - & - \\
\hline $65-74$ very poor health & $4.22^{* * *}$ & $28.90^{* *}$ & $21.47^{* *}$ & - \\
\hline $75+$ good health & - & - & - & - \\
\hline $75+$ fair health & - & $3.65^{* *}$ & - & - \\
\hline $75+$ poor health & $3.05^{*}$ & $8.37^{* * *}$ & $4.16^{* *}$ & - \\
\hline $75+$ very poor health & $8.40^{* *}$ & $11.83^{*}$ & $13.57^{* * *}$ & - \\
\hline \multicolumn{5}{|c|}{ Age*Household Composition } \\
\hline $25-44$ Single Person & $2.02^{* * *}$ & $3.22^{* * *}$ & $3.33^{* * *}$ & - \\
\hline 45-54 Single Person & - & $4.04^{* * *}$ & $2.77^{* *}$ & - \\
\hline 55-64 Single Person & $1.72^{*}$ & $2.54^{* * *}$ & $2.29^{*}$ & - \\
\hline 65-74 Single Person & - & - & - & - \\
\hline $75+$ Single Person & - & - & $2.03^{*-}$ & - \\
\hline \multicolumn{5}{|l|}{ Age* Income $^{*}$} \\
\hline $25-44$ Second quintile & - & - & - & - \\
\hline 25-44 Middle quintile & - & - & $2.01^{*}$ & - \\
\hline $25-44$ Fourth quintile & - & - & - & $1.49^{*}$ \\
\hline 25-44 Bottom quintile & - & $4.82^{* * *}$ & $2.21^{*}$ & - \\
\hline $45-54$ Second quintile & - & - & - & - \\
\hline 45-54 Middle quintile & - & - & - & $0.69^{*}$ \\
\hline $45-54$ Fourth quintile & - & $2.56^{*}$ & - & - \\
\hline $45-54$ Bottom quintile & - & $2.68^{*}$ & - & - \\
\hline 55-64 Second quintile & - & - & - & $0.57^{*}$ \\
\hline 55-64 Middle quintile & $0.23^{*}$ & - & - & - \\
\hline 55-64 Fourth quintile & - & - & - & - \\
\hline 55-64 Bottom quintile & - & - & - & - \\
\hline $65-74$ Second quintile & - & - & - & - \\
\hline 65-74 Middle quintile & - & - & - & - \\
\hline $65-74$ Fourth quintile & - & - & - & - \\
\hline 65-74 Bottom quintile & - & - & - & - \\
\hline $75+$ Second quintile & - & - & - & - \\
\hline $75+$ Middle quintile & - & - & - & - \\
\hline $75+$ Fourth quintile & $0.31^{*}$ & - & - & $0.56^{*}$ \\
\hline $75+$ Bottom quintile & - & - & - & - \\
\hline
\end{tabular}

Significance levels: ${ }^{*}<0.05{ }^{* *}<0.01 ;{ }^{* * *}<0.001$. 
Work is increasingly recognised as the best form of welfare in twenty-first century capitalist society (DWP, 2010), not only because work usually pays better than welfare, but because work helps to promote wellbeing, as we observe here: the odds of 'dissatisfaction' amongst adults not in work are nearly three times greater than those in work, according to the survey data. To this end, the UK's new 'welfare-to-work' policies, including the 'Work Programme' and the new means-tested benefit 'Universal Credit' seek to ensure 'welfare that works'; a life in work rather than a life on benefits (Welfare Reform Act, 2012). Consequently, labour market conditionality now applies to most sections of the adult working age population and the principles at stake here appear to be attracting support amongst the British public (Park et al., 2011). In many ways - and from the perspective of SWB - the policy aim is laudable; there are obvious benefits and gains if more out of work adults are able to find decent, meaningful jobs. However, there are growing concerns over the level of state regulation in the name of labour market 'activation'. There may be policy limits to 'activation', including some of the present structural concerns over the lack of employment opportunities on offer, as well as the high cost of childcare faced by many working parents. The limits of these policies are now being tested by some of the most vulnerable sections of British society, who maintain that their needs are not being respected under the new regulatory regime. For instance, two-thirds of lone parents now targeted by 'activation' policy, claim that taking a paid job is not appropriate in their circumstances (Rafferty and Wiggan, 2011). Instead, they express a strong preference for caring for their own children themselves. Likewise, the government policy to encourage and assist disabled people off benefits and in to paid work is surrounded with controversy for ignoring the needs of disabled people, and societal barriers to their full and equal labour market participation (McCartney, 2012; Patrick, 2012). Paid work will not be appropriate in every circumstance and not all adults will benefit from being 'activated'. In this inquiry, employment status had little effect on life 'satisfaction' for disabled adults, in stark contrast with the findings for the general British population. Many older adults in retirement report relatively high levels of SWB; empirical research continues to show most lead socially active and productive lives. The UK's 'active ageing' strategy, therefore, needs to support local 'big society' initiatives, and thus extend beyond the rather narrow focus on employment opportunities (Deeming, 2009).

Whether increasing income raises the experience of wellbeing is a matter of major debate (Diener et al., 2009b). In this study, we found little evidence to suggest that income makes an independent contribution to SWB across our four dimensions. However, we should recognise the need for more sophisticated modelling techniques that include both individual and societal factors to probe this complex relationship (Deeming and Hayes, 2012). It is noticeable, and also worrying, that there has been a distinct shift in policy away from faith in income and material recourses to solve some of the complex and deep-rooted social 
problems we see in the UK (e.g., Field, 2010); and while we wait for research to uncover more 'truths', we should not lose sight of the powerful effect that income and wealth has on important social outcomes (Hills et al., 2010; Rowlingson, 2011).

Although we find women in Britain are more likely to lead 'fulfilled' lives than men, a finding that is very much in tune with some of the emerging international evidence (OECD, 2012), it is also very apparent that women are more 'anxious' about and 'stressed' with daily life. This is as a result of combining employment and family care, as Lewis (2009) argues. Future prospects are not good either with greater labour market regulation enforcing this duality. Many working mothers dislike or reject the new 'one-size-fits-all' regulatory framework being imposed upon them by 'welfare-to-work'. Ensuring that families, especially single parent families, are able to both support themselves and to care for their dependants without material disadvantage continues to be a major challenge for social policy in the UK. The issues raised here are symptomatic of more general shifts in the balance of work and family life, with ever greater family diversity and changes in the labour market. Ageing populations and changing family structures present new challenges. Policymakers have been slow to respond to the 'new social risks' of modern societies in the twenty-first century as Taylor-Gooby (2004) argues. Generally speaking, living alone is not good for wellbeing as the study findings and a growing body of research evidence indicate (Stack and Eshleman, 1998). Solo living often results in isolation from the privileges and obligations of cohabited (including married) life. The ties of cohabitation help to establish a basic sense of belonging and security; SWB is clearly affected where such ties are lacking. Perhaps a growing area of concern for the policy of wellbeing is the growing numbers who live alone in Britain: a trend which shows little sign of abating (Chandler et al., 2004). Although the ageing population has contributed to this demographic, solo living is a growing trend across all age groups in the adult population. 'Individualisation' means people are inextricably linked to the institutions of the labour market and welfare state, while traditional forms of family and community life lose more and more of their meaning. The new institutions and social structures increasingly regulate life, with demands and entitlements that are not wholly addressing the needs of individuals, and nor are they addressing the needs of family variety in the twenty-first century. Policymakers face pressing issues over intergenerational equity, as the study findings indicate wellbeing is not evenly distributed between the generations (Willetts, 2010).

Structural components of ethnic disadvantage persist, despite various employment initiatives and legislation (Virk, 2012). The results suggest that SWB among unemployed people in BME groups are a particular concern. The interplay of factors at stake here is likely to be complex as Berthoud (2000) suggests, but will include known factors such as overt and 'hidden' discrimination, expectations, stereotypes, alienation, family and economic structures. Education helps to 
promote wellbeing, and is well-recognised as a cultivating force within society (Nussbaum, 1997). However, the recent reforms to higher education in England are, according to some critics such as Barr (2012), a retrograde step that is likely to undermine the quality of education and the goal of widening participation. Students from poorer backgrounds already experience a range of structural disadvantages in the higher-education system, relating to economic, social, and cultural capital (Lehmann, 2009). Expensive loans are likely to further impede access and weaken participation, stifling the prospects of social mobility and increased wellbeing for young people from poorer working-class backgrounds.

We find that people living in poor health - which often means coping with a longstanding illness - are amongst the most vulnerable members of British society, reporting the lowest levels of wellbeing. ${ }^{6}$ There are clear links between age and health in the data as expected, but poor health also interacts with other forms of social and material circumstance, such as unemployment, low income, low 'social class' and self-rated disability (Clark and Oswald, 1994). Clearly, social policy has to address this great complexity and diversity. The Coalition government's response is increased personalisation and choice. New strategies demand that individuals take greater responsibility for their own agency and 'wellness'. Power and responsibility is being devolved to the local level; 'wellness services' in each locality are to be held accountable for the wellbeing of their local populations (Health and Social Care Act, 2012). ${ }^{7}$ The danger of this fiercely consumerist and individualist self-directed approach to policy is the increasing fragmentation and marketisation of the social and human services; particularly evident in the new public health paradigm (Bambra et al., 2011), social care policy (Glendinning, 2012) and housing policy (Lund, 2011). Better government regulation of the private rental sector is urgently required to promote health and wellbeing, although this is not a priority for the Coalition government. Nearly 40 per cent of privately rented homes fail the government's Decent Homes Standard, and people in this sector express high levels of 'dissatisfaction' with their accommodation (DCLG, 2012). ${ }^{8}$ Moreover, many vulnerable families in Britain are being funnelled into the bottom end of this market, resulting from the caps on housing benefit imposed by the new system of Universal Credit (Harding, 2011). The policy turn to individual consumerism and the market, with the desire to devolve responsibility from Whitehall, and arguably shift blame, threatens the very foundations of human health and wellbeing in the UK at a time when the influence of the wider social context is being ignored. There is an urgent need to emphasise the social, given the direction of current policy in Britain.

\section{Conclusions}

Research into wellbeing, both the subjective (SWB) components and the substantive (i.e., holistically understood) aspects of human flourishing belong to 
the core business of social policy (Dean, 2012). Here we have focused on SWB and the emerging MNW programme that offers much potential for the development of social policy, informed by the rigorous analysis of survey data within the social scientific tradition (Byrne, 2011). There are, of course, a number of cautions and limitations attached to the study findings. Correlations in this field should not be treated as evidence of one-way causation from factors to 'happiness', as Thin (2012) argues. The cross-sectional survey data used here is limited when it comes to studying changes in SWB over time and/or across the lifecourse. Longitudinal studies, cohorts or panel surveys are required for modelling and interpreting cross-temporal comparisons that shed light on whether the same population has become happier (Davies, 1994). Researchers may wish to consider a radically different approach to the interpretation of this survey data using a set-theoretic method for example. Finally, and more conceptually, we are a long way off from a world in which emotional fulfilment replaces ideas about maximising economic growth, and although social policy is making progress, there would be grave dangers in any single-minded pursuit of this (Burchardt, 2006). The value of social policy is that it recognises the plurality of human ends and needs (not just ideas relating to 'happiness' or SWB), and as such it invokes our social values and principles for thinking about resources, material circumstances, and their distributions.

In terms of future work, there is a more general need to examine more closely the relationship between SWB and mental health issues (Beaumont and Thomas, 2012). Further work should also consider disparities in SWB within and between minority ethnic groups within society (Burton et al., 2010; Platt, 2011). Finally, the four overall SWB monitoring questions now included in ONS social surveys are designed to collect different types of information from respondents about their own wellbeing; ONS argue that the four SWB constructs and measures can and do stand alone, and while there is a literature to support this thinking, future work might also test some of these assumptions since these measures and constructs are now widely used internationally.

\section{Acknowledgements}

I am grateful to the referees and to the Editors for helpful comments on an earlier version of this paper. The study was supported by ESRC grant ES/Koo1353/1 'New Cultural Contradictions in Society'. The ONS material used in this study is Crown Copyright and has been used with relevant permissions. The study is registered with the UK Data Archive (datasets for usage: 63168, study number: 6893).

\section{Notes}

1 ONS data are freely available to academic researchers via the UK Data-Archive upon registration although some datasets do require a special licence (www.data-archive.ac.uk).

2 Two independent variables may be said to interact if the effect of one of the variables differs depending on the level of the other variable. 
3 Multicollinearity usually arises when there is a strong linear relationship among two or more independent variables; although this may be an issue, usually it does not reduce the predictive power or reliability of the model as a whole. In practice, we rarely face perfect multicollinearity in a dataset. Differences between the bivariate and multivariate model help to alert us to potential issues. For instance, there appears to be some collinearity between disability and health status in the multivariate analysis as discussed in the findings. Another clue is provided by the covariance matrix among the regression coefficients.

4 The ONS 'economically inactive' group includes people who are neither in employment nor unemployed. This group includes, for example, those who are looking after family members and those who have retired from work and full-time students.

5 See www.dwp.gov.uk/policy/welfare-reform/legislation-and-key-documents/welfarereform-act-2012/, or www.legislation.gov.uk/ukpga/2012/5/introduction/enacted.

6 The prevalence of longstanding illness in the UK is significant, around 40 per cent according to some estimates, and forecasts look set to rise with population ageing (Craig and Hirani, 2010).

7 See www.legislation.gov.uk/ukpga/2012/7/contents/enacted.

8 Thirty-seven per cent of privately rented homes fail the government's Decent Homes Standard, compared to 26 per cent of owner-occupied dwellings, 22 per cent of local authority dwellings and 18 per cent of housing association dwellings (DCLG, 2012: Annex Table 4.1).

\section{References}

Anand, P., Hunter, G., Carter, I., Dowding, K. and van Hees, M. (2009), 'The development of capability indicators', Journal of Human Development and Capabilities, 10: 1, 125-52.

Bambra, C., Smith, K. E., Garthwaite, K., Joyce, K. E. and Hunter, D. J. (2011), 'A labour of Sisyphus? Public policy and health inequalities research from the Black and Acheson Reports to the Marmot Review', Journal of Epidemiology and Community Health, 65: 5, 399-406.

Barr, N. (2012), 'The Higher Education White Paper: the good, the bad, the unspeakable - and the next White Paper', Social Policy and Administration, 46: 5, 483-508.

Beaumont, J. and Thomas, J. (2012), Measuring National Well-being: Health: ONS.

Berthoud, R. (2000), 'Ethnic employment penalties in Britain', Journal of Ethnic and Migration Studies, 26: 3, 389-416.

Blanchflower, D. G. and Oswald, A. J. (2008), 'Is well-being U-shaped over the life cycle?', Social Science and Medicine, 66: 8, 1733-49.

Bok, S. (2010), Exploring Happiness: From Aristotle to Brain Science, New Haven: Yale University Press.

Burchardt, T. (2006), 'Happiness and social policy: barking up the right tree in the wrong neck of the woods', in L. Bauld, K. Clarke and T. Maltby (eds.), Social Policy Review, 18, Bristol: Policy Press, pp. 145-64.

Burton, J., Nandi, A. and Platt, L. (2010), 'Measuring ethnicity: challenges and opportunities for survey research', Ethnic and Racial Studies, 33: 8, 1332-49.

Byrne, D. (2011), Applying Social Science: The Role of Social Research in Politics, Policy and Practice, Bristol: Policy Press.

Chandler, J., Williams, M., Maconachie, M., Collett, T. and Dodgeon, B. (2004), 'Living alone: its place in household formation and change', Sociological Research Online, 9: 3, www.socresonline.org.uk/9/3/chandler.html (accessed 18 February 2013).

Clark, A. E. (2006), A Note on Unhappiness and Unemployment Duration, Paris: Paris-Jourdan Sciences Economics.

Clark, A. E. and Oswald, A. J. (1994), 'Unhappiness and unemployment', The Economic Journal, 104: 424, 648-59.

Craig, R. and Hirani, V. (eds.) (2010), Health Survey for England 2009: Health and Lifestyles Summary of Key Findings, Leeds: The Health and Social Care Information Centre. 
Crockett, A. (2006), Weighting the Social Surveys, Economic and Social Data Service, www.esds.ac.uk/government/docs/weighting.pdf (accessed 18 February 2013).

Davies, R. B. (1994), 'From cross-sectional to longitudinal analysis', in A. Dale and R. B. Davies (eds.), Analysing Social and Political Change: A Casebook of Methods, London: Sage, pp. 20-40.

Department for Communities and Local Government (DCLG) (2012), English Housing Survey 2010-2011: Household Report, London: DCLG.

Dean, H. (2010), Understanding Human Need, Bristol: Policy Press.

Dean, H. (2012), Social Policy, Second Edition, Cambridge: Polity.

Deaton, A. (2008), 'Worldwide, residents of richer nations more satisfied', Perspectives, 160, www.nzbr.org.nz/site/nzbr/files/perspectives/issue16o.pdf (accessed 18 February 2013).

Deeming, C. (2009), “'Active ageing" in practice: a case study in East London, UK', Policy and Politics, 37: 1, 93-111.

Deeming, C. and Hayes, D. (2012), 'Worlds of welfare capitalism and wellbeing: a multilevel analysis', Journal of Social Policy, 41: 4, 811-29.

Department of Work and Pensions (DWP) (2010), Universal Credit: Welfare that Works, Cm 7957, London: DWP.

Diener, E. (ed.) (2009a), Assessing Well-Being: The Collected Works of Ed Diener, Social Indicators Research Series 39, Dordrecht, Springer.

Diener, E. (2009b), 'Assessing subjective well-being: progress and opportunities', in E. Diener (ed.), Assessing Well-Being: The Collected Works of Ed Diener, Social Indicators Research Series 39, Dordrecht: Springer, pp. 25-65.

Diener, E., Lucas, R. E., Schimmack, U. and Helliwell, J. F. (2009a), Well-Being for Public Policy, Oxford: Oxford University Press.

Diener, E., Kahneman, D., Arora, R., Harter, J. and Tov, W. (2009b), 'Income's differential influence on judgments of life versus affective well-being', in E. Diener (ed.), Assessing WellBeing: The Collected Works of Ed Diener, Social Indicators Research Series 39, Dordrecht: Springer, pp. 233-45.

Dobson, A. J. (2001), Introduction to Generalized Linear Models, Second Edition, London: Chapman \& Hall.

Dolan, P. and Metcalfe, R. (2012), 'Measuring subjective wellbeing: recommendations on measures for use by national governments', Journal of Social Policy, 41: 2, 409-7.

Dolan, P., Peasgood, T. and White, M. (2008), 'Do we really know what makes us happy? A review of the economic literature on the factors associated with subjective well-being', Journal of Economic Psychology, 29: 1, 94-122.

Field, F. (2010), The Foundation Years: Preventing Poor Children Becoming Poor Adults, London: Cabinet Office.

Glendinning, C. (2012), 'Home care in England: markets in the context of under-funding', Health and Social Care in the Community, 20: 3, 292-9.

Graham, C. (2011), The Pursuit of Happiness: Toward an Economy of Well-Being, Washington, DC: Brookings Institution.

Harding, R. (2011), 'The implications of the changes to housing benefit', Journal of Poverty and Social Justice, 19: 2, 175-9.

Harvie, D., Slater, G., Philp, B. and Wheatley, D. (2008), 'Economic well-being and British regions: the problem with GDP per capita', Review of Social Economy, 67: 4, 483-505.

Hills, J., Brewer, M., Jenkins, S., Lister, R., Lupton, R., Machin, S., Mills, C., Modood, T., Rees, T. and Riddell, S. (2010), An Anatomy of Economic Inequality in the UK: Report of the National Equality Panel, London: Centre for Analysis of Social Exclusion, The London School of Economics and Political Science.

Hosmer, D. W. and Lemeshow, S. (2000), Applied Logistic Regression, Second Edition, New York: John Wiley \& Sons.

Karlsen, S., Becares, L. and Roth, M. (2012), 'Understanding the influence of ethnicity on health', in G. Craig, K. Atkin, S. Chattoo and R. Flynn (eds.), Understanding 'Race' and Ethnicity: Theory, History, Policy, Practice, Bristol: Policy Press, pp. 115-32. 
Layard, R. (2005), Happiness: Lessons from a New Science, London: Allen Lane.

Lehmann, W. (2009), 'Becoming middle class: how working-class university students draw and transgress moral class boundaries', Sociology, 43: 4, 631-47.

Lewis, J. (2009), Work-Family Balance, Gender and Policy, Cheltenham: Edward Elgar.

Lund, B. (2011), Understanding Housing Policy, Second Edition, Bristol: Policy Press.

McCartney, M. (2012), 'The disturbing truth about disability assessments', British Medical Journal, 345: e5347

Nussbaum, M. C. (1997), Cultivating Humanity: A Classical Defense of Reform in Liberal Education, Cambridge, MA: Harvard University Press.

OECD (Organisation for Economic Co-operation and Development) (2012), Your Better Life Index, www.oecdbetterlifeindex.org/wpsystem/wp-content/uploads/2012/05/EXECUTIVESUMMARY1.pdf (accessed 18 February 2013).

ONS (Office for National Statistics) (2011a), Analysis of Experimental Subjective Wellbeing: Data from the Annual Population Survey, www.ons.gov.uk/ons/dcp171776_257882.pdf (accessed 18 February 2013).

ONS (2011b), Initial Investigation into Subjective Wellbeing from the Opinions Survey, Newport, Wales: ONS, www.ons.gov.uk/ons/dcp171776_244488.pdf (accessed 18 February 2013).

ONS (2011c), National Statistics Opinions Survey: Technical Report (April 2011), Newport, Wales: ONS.

ONS (2011d), Regional, Sub-Regional and Local Gross Value Added 2010, www.ons.gov.uk/ons/ dcp171778_250356.pdf (accessed 18 February 2013).

ONS (2012), ONS Opinions Survey, Well-Being Module, April, June, July, August and September, 2011, Social Survey Division,Colchester, Essex, www.esds.ac.uk .

ONS (n.d.), ONS Opinions Survey, referencestables_tcm77-245640.xls, Table 2, www.ons. gov.uk/ons/rel/wellbeing/measuring-subjective-wellbeing-in-the-uk/investigation-ofsubjective-well-being-data-from-the-ons-opinions-survey/reft.xls (accessed 18 February 2013).

Oswald, A. J. and Powdthavee, N. (2008), 'Does happiness adapt? A longitudinal study of disability with implications for economists and judges', Journal of Public Economics, 92: 5-6, 1061-77.

Park, A., Clery, E., Curtice, J., Phillips, M. and Utting, D. (eds.) (2011), British Social Attitudes, 28, 2011-12 Edition, London: Sage.

Patrick, R. (2012), 'All in it together? Disabled people, the Coalition and welfare to work', Journal of Poverty and Social Justice, 20: 3, 307-22.

Platt, L. (2011), Inequality within Ethnic Groups, York: JRF.

Parliamentary Office of Science and Technology (POST) (2012), Measuring National Wellbeing, London: POST.

Rafferty, A. and Wiggan, J. (2011), 'Choice and welfare reform: lone parents' decision making around paid work and family life', Journal of Social Policy, 40: 2, 275-93.

Roulstone, A. and Prideaux, S. (2012), Understanding Disability Policy, Bristol: Policy Press.

Rowlingson, K. (2011), Does Income Inequality Cause Health and Social Problems?, York: JRF.

Stack, S. and Eshleman, J. R. (1998), 'Marital status and happiness: a 17-nation study', Journal of Marriage and Family, 60: 2, 527-36.

Stiglitz, J., Sen, A. and Fitoussi, J.-P. (2010), MIS-Measuring Our Lives: Why GDP Doesn't Add Up (The Report of the Commission on the Measurement of Economic Performance and Social Progress), New York: The New Press.

Stratton, A. (2010), 'David Cameron aims to make happiness the new GDP: Prime minister acts on pledge to find out what makes the nation content', The Guardian, Sunday, 14 November, www.guardian.co.uk/politics/2010/nov/14/david-cameron-wellbeing-inquiry (accessed 18 February 2013).

Taylor-Gooby, P. (ed.) (2004), New Risks, New Welfare: The Transformation of the European Welfare State, Oxford: Oxford University Press.

Taylor, D. (2011), 'Wellbeing and welfare: a psychosocial analysis of being well and doing well enough', Journal of Social Policy, 40: 4, 777-94. 
Thin, N. (2012), Social Happiness: Theory into Policy and Practice, Bristol: Policy Press.

Virk, B. (2012), 'Minority ethnic groups in the labour market', in S. Karlsen, L. Becares and M. Roth (eds.), Understanding 'Race' and Ethnicity: Theory, History, Policy, Practice, Bristol: Policy Press, pp. 167-89.

Willetts, D. (2010), The Pinch: How the Baby Boomers Took their Children's Future - and Why They Should Give it Back, London: Atlantic Books.

\section{Appendix: ONS Opinions Survey}

This survey is carried out by ONS to allow reliable information on topics of immediate policy interest. Recent topics have included Charitable Giving, Attitudes to Ageing, Migration, Public Perceptions of Tax and Well-being. It uses a random probability sample stratified by: region, the proportion of households with no car, the proportion in the National Statistics socio-economic categories one to three and the proportion of people aged over sixty-five years. In common with other ONS social surveys, it uses the Royal Mail's small-user postcode address file to draw the sample from across Great Britain. Participation is purely voluntary and interviewers only call at addresses where no refusal has been made to the advance letter. The interviewer will make up to twenty calls to an address at different times in the day and the week to try to make contact, after which the address is marked as a non-contact. The interviewer uses a Kish grid to randomly select one of the adults (aged sixteen and over) living within the household for interview. All interviews are carried out face-to-face (except for a very small number of telephone reissues) by ONS interviewers trained to carry out National Statistics surveys. The final achieved sample is around 1,100 adults (aged sixteen and over) per month with an approximate overall survey response rate of around 60 per cent. The data presented in this article are taken from the April, June, July and August 2011 Opinions Survey and provide a combined sample size of around 4,200 adults in Great Britain aged sixteen and over. All calculations and estimates in this study are weighted. By weighting the estimates, we ensure that they are more representative of the population but with the assumption that those people who did not respond to the survey would provide on average the same ratings of subjective wellbeing as those that do. There are two weights in the Opinions Survey: first, a weight that adjusts for the differences in the probability of an individual being selected due to different household sizes and sample design and, second, a weight that calibrates the sample so that it is representative of the overall population levels in Great Britain by age, sex and region. 